\title{
Simulating debris flows through a hexagonal cellular automata model: SCIDDICA $\mathbf{S}_{3-\text { hex }}$
}

\author{
D. D'Ambrosio ${ }^{1}$, S. Di Gregorio ${ }^{1}$, and G. Iovine ${ }^{2}$ \\ ${ }^{1}$ Dept. of Mathematics and Centre of High-Performance Computing, University of Calabria, 87036 Arcavacata di Rende, CS, \\ Italia \\ ${ }^{2}$ CNR-IRPI, via Cavour, 87030 Rende, CS, Italia
}

Received: 7 October 2002 - Revised: 12 May 2003 - Accepted: 13 May 2003

\begin{abstract}
Cellular Automata (CA) represent a formal frame for dynamical systems, which evolve on the base of local interactions. Some types of landslide, such as debris flows, match well this requirement.

The latest hexagonal release $\left(\mathrm{S}_{3-\text { hex }}\right)$ of the deterministic model SCIDDICA, specifically developed for simulating debris flows, is described. For CA simulation purposes, landslides can be viewed as a dynamical system, subdivided into elementary parts, whose state evolves exclusively as a consequence of local interactions within a spatial and temporal discretum. Space is the world of the CA, here constituted by hexagonal cells. The attributes of each cell ("substates") describe physical characteristics. For computational reasons, the natural phenomenon is "decomposed" into a number of elementary processes, whose proper composition makes up the "transition function" of the CA. By simultaneously applying this function to all the cells, the evolution of the phenomenon can be simulated in terms of modifications of the substates.
\end{abstract}

SCIDDICA $\mathrm{S}_{3-\text { hex }}$ exhibits a great flexibility in modelling debris flows. With respect to the previous releases of the model, the mechanism of progressive erosion of the soil cover has been added to the transition function. Considered substates are: altitude; thickness and energy of landslide debris; depth of erodable soil cover; debris outflows. Considered elementary processes are: mobilisation triggering and effect $\left(T_{1}\right)$, debris outflows $\left(I_{1}\right)$, update of landslide debris thickness and energy $\left(I_{2}\right)$, and energy loss $\left(T_{2}\right)$.

Simulations of real debris flows, occurred in Campania (Southern Italy) in May 1998 (Sarno) and December 1999 (San Martino V.C. and Cervinara), have been performed for model calibration purposes; some examples of analysis are briefly described. Possible applications of the method are: risk mapping, also based on a statistical approach; evaluating the effects of mitigation actions (e.g. stream deviations, topographic alterations, channelling, embankments, bridges, etc.) on flow development.

Correspondence to: G. Iovine (g.iovine @ irpi.cnr.it)

\section{Introduction}

Nature's laws are basically founded on principles of conservation (e.g. conservation of mass, momentum, energy), which have to be expressed in appropriate mathematical forms. The possibility of describing phenomena in terms of differential equations marked the difference between "strong" (highly predictive) and "weak" (purely descriptive) science. An analytical solution of such equations returns the state of the system in the continuum space-time. Nevertheless, analytical solutions fail for some problems of "strong" science, when dealing with complex phenomena (e.g. turbulence problems in fluid-dynamics). These latter cases can only be treated as weak-science problems, in terms of experimental observations: for instance, the development of turbulence in an aircraft wing can be properly analysed (and solved) only by examining a scaled mock-up of the wing, in the wind tunnel.

Attempts of quantitative modelling of complex natural phenomena through approximated numerical methods (commonly based on a discretisation of space and time) mainly developed thanks to the growth in computer power. These methods (e.g. for slope stability analyses: Little and Price, 1958; Morgenstern and Price, 1967; Withman and Bailey, 1967; Bromhead, 1986) greatly extended the class of problems which can be solved in terms of differential equation systems; however, many problems still remained unmanageable. Meanwhile, innovative numerical methods emerged from alternative computational paradigms such as cellular automata (CA), neuronal nets, genetic algorithms, etc. (von Neumann, 1966; Kohonen, 1984; Holland, 1975).

Both differential and alternative approaches rely on the dual concept of "modelling and simulation". Nowadays, assessing hazard conditions related to complex natural phenomena increasingly takes advantage of computer-assisted analyses and simulations (e.g. for landslide hazard assessment, cf. Van Westen, 1994; Carrara et al., 1995; Aleotti and Chowdury, 1999; Guzzetti et al., 1999).

In particular, Cellular Automata (CA) are a powerful tool for modelling natural and artificial systems which can be 
specified in terms of local interactions among their constituent parts (Burks, 1970; Wolfram, 1986, 2002). Some types of landslides, such as debris flows (Johnson and Rodine, 1984), match well this requirement.

For CA modelling purposes (Di Gregorio and Serra, 1999), landslides can be viewed as a dynamical system which evolves within a limited portion of the space, tessellated into regular cells. The "state" of each cell describes the physical characteristics of the corresponding portion of space: at this purpose, proper cell attributes (substates) must be selected: e.g. altitude, depth of soil cover, thickness of landslide debris, landslide energy. The state of each cell is therefore expressed by the Cartesian product of all the considered substates. Elementary processes constitute the transition function $(\sigma)$ of the model: it is made of a set of rules which describe local processes constituting the overall phenomenon.

At the beginning of the simulation, cell states are initialised by means of input matrices. Model parameters have also to be assigned in this phase, by taking into consideration their physical/empirical meaning. By simultaneously applying the transition function to all the cells, at discrete steps, states are changed and the evolution of the phenomenon can be simulated.

SCIDDICA is a deterministic CA-model, recently developed for simulating flow-like landslides. In the present paper, the latest hexagonal release $\left(S_{3-\text { hex }}\right)$ of the model is described. SCIDDICA $S_{3-\text { hex }}$ has preliminarily been calibrated, by considering several real cases of debris flows occurred in Campania (Southern Italy) in May 1998 and December 1999. Examples of simulation of debris flows, selected among those triggered on the southern slope of Pizzo d'Alvano massif by the May 1998 hydrogeological event, are briefly commented.

\section{Cellular automata modelling}

\subsection{Microscopic approaches to fluid-dynamics}

CA introduced a new approach in treating some complex systems, whose behaviour may be expressed in terms of local laws. The complexity of the system emerges from the interactions of its elementary (cellular) units, by applying relatively simple local rules.

A CA can be intuitively considered as a d-dimensional space (the cellular space), partitioned into cells of uniform size. Each cell embeds an identical computational device: the finite automaton $(f a)$. Input for each $f a$ is given by the states of the $f a$ located in the neighbouring cells. At this purpose, neighbourhood conditions have to be determined through a geometrical pattern, which is invariant in time and constant over the cells. At time $t=0, f a$ are in arbitrary states and describe the initial conditions of the system. The CA evolves by simultaneously changing all the states, at discrete times, by applying the transition function to the cellular space (Di Gregorio and Serra, 1999).
Fluid-dynamics is an important field of CA application: lattice gas automata models (Hardy et al., 1976; Frisch et al., 1986) were introduced for describing the motion and collision of "particles" on a grid. It was shown (Rothman and Zaleski, 1997) that such models can simulate fluid dynamical properties; the continuum limit of these models leads to the Navier-Stokes equations. Lattice gas models can either be regarded as microscopic or mesoscopic, as they describe the motion of fluid "particles" - actually "fluid tokens" which interact by scattering. An advantage of lattice gas models is that the simplicity of these particles, and of their interactions, allow for the simulation of a large number of particles, thus making it possible to observe the birth of macroscopic flow patterns.

A different approach characterises the so-called lattice Boltzmann models (McNamara and Zanetti, 1988; Succi et al., 1991): the state variables can take continuous values, as they are supposed to represent the density of fluid particles, endowed with certain properties, located in each cell (space and time are discrete, as in lattice gas models).

Both lattice gas- and lattice Boltzmann models have been applied for the description of fluid turbulence (Succi et al., 1988). Nevertheless, their range of applicability does not generally include macroscopic phenomena in three "effective" dimensions - e.g. evolution of debris flows in a 3-Dcontext.

\subsection{Modelling macroscopic phenomena}

Surface-flow phenomena, like debris flows, take place on a large space scale. When dealing with such processes, it is necessary to define a correspondence between the system and its evolution, on one side, and the model and its simulations, on the other. Primarily, the dimension of the cell and the time correspondence to a CA step must be fixed. These latter are defined as "global parameters", as their values are equal for all the cellular space (other global parameters are commonly necessary for simulation purposes). In order to fix the values of such essential global parameters, further points must be considered, especially when the phenomenon is complex and involves time and/or space heterogeneity, in the sense better specified later on.

The state of the cell must account for all the characteristics, which are assumed to be relevant to the evolution of the system: these refer to the space portion of the cell. Each characteristic corresponds to a substate; permitted values for a substate must form a finite set. The set of the possible states of a cell is given by the Cartesian product of the sets of the substates. In case one characteristic (e.g. a physical quantity) is usually expressed in terms of a continuous variable referred to a space point, the cell size must be chosen small enough so that one single value can properly be attributed. The continuity of the variable is not a problem: in practical cases, the utilised variables have a finite number of significant digits, and a finite range of permitted values; the set of utilised values can be extremely large, but is always finite. 
The size of the cell must also be large enough, in order allow for a macroscopic approach; nevertheless, it has to be much smaller than the length scale of appreciable variations in the substates (so that they can be considered as constant within each cell). These are reminiscences of the approximation, which is typical of classical rheologic models, where limit operations are performed, letting the size of the elementary cell shrink to 0 , and a continuum description (i.e. partial differential equations) possible. Our approach differs in its use of discrete space (cells), and discrete time increments (steps): accordingly, continuum limit operations are not required.

As well as the state of the cell can be decomposed in substates, the transition function may be split into local interactions: the "elementary" processes. Different elementary processes may involve different neighbourhoods; the CA neighbourhood is given by the union of all the neighbourhoods associated to each processes. If the neighbourhood of an elementary process is limited to a single cell, such process is an "internal transformation".

The choice of the cell dimension, of the CA clock and of the neighbourhood is made by considering the peculiarities of the elementary processes. A process affects a larger surrounding of cells in a CA step, as faster is its propagation within the cellular space: in CA, velocity depends on the CA clock and the cell dimension.

\subsection{Surface-flow modelling through CA}

Macroscopic phenomena involving surface-flows can be modelled through two-dimensional CA, if the third dimension (the height) can be managed as a property of the cell (i.e. a substate). This condition permits to adopt a simple, but effective, strategy based on the hydrostatic equilibrium principle in order to compute the cell outflows (Di Gregorio and Serra, 1999).

Let us focus for simplicity on a single CA cell (individuated as the "central" cell) of the two-dimensional space: it is considered limited to the universe of its neighbourhood, which consists of $m$ cells (the central cell and its adjacent cells). Indexes are utilised to individuate the central cell $(0)$ and the adjacent ones $(1,2, \ldots, m-1)$, respectively.

The outflows from the central cell to the adjacent cells depend on the hydrostatic pressure gradients across the cells, due to differences in "heights" (for instance, for a landslide: altitude plus landslide debris thickness).

At step $t$, two quantities are identified in the central cell: the fixed part $(q(0))$ and the mobile part $(p)$ of its height. The mobile part represents a quantity that can be distributed to the adjacent cells (in our example, the landslide debris thickness); the fixed part cannot change during the simulation (e.g. the altitude related to the unerodable bedrock). Accordingly, the height of the central cell is given by the sum of two terms $p+q(0) ; q(i), 1 \leq i \leq m-1$ is the height of the $i$-th adjacent cell of the neighbourhood - note that the distinction between mobile and fixed part is not necessary in the other cells of the neighbourhood, as only the mobile part of the central cell may be distributed.

At step $t+1$, the outflow from the central cell to the $i$-th neighbouring cell is denoted by $f(i), 0 \leq i<m$, where $f(0)$ is the part of $p$ which is not distributed. Let $q^{\prime}(i)=$ $q(i)+f(i), 0 \leq i<m-1$ be the sum of the content (at step $t$ ) of a neighbouring cell, plus the flow coming from the central cell, and let $q_{\min }^{\prime}$ be the minimum value for $q^{\prime}(i)$. The determination of the outflows, from the central cell to the adjacent cells, is therefore based on the local minimisation of the differences in "height", as described by the following expression:

$\sum_{i=0}^{m-1}\left(q^{\prime}(i)-q_{\min }^{\prime}\right)$

Theorems concerning the "minimisation" algorithm (i.e. the algorithm for the minimisation of differences) and the relative discussion are not treated here; they can be found in Di Gregorio and Serra (1999).

As the minimum "imbalance" conditions can be achieved also in more than one single CA step, a relaxation rate which depends on both the cell size and the duration of the CA step - must be considered. The relaxation rate $p_{r}$, specified by a multiplicative factor, can assume values between 0 and $1\left(0<p_{r} \leq 1\right)$.

The mentioned method constitutes a valid CA approximation only in cases of simple evolution of the phenomenon to be simulated: integrations would become necessary in more complex cases, e.g. when conditions of equilibrium to be accounted for in the minimisation algorithm can not ignore inertial effects (related to high-energy conditions). Integrations may also consist of new local interactions and/or internal transformations.

The above described minimisation algorithm, opportunely adapted, has also been applied for modelling other types of surface-flows, such as lava flows and soil erosion by water (Barca et al, 1994; D’Ambrosio et al., 2001).

\subsubsection{Previous releases of SCIDDICA}

SCIDDICA was originally developed for simulating simple cases of flow-like landslides. In its successive releases, higher complexity was essentially managed, by progressively adding new local interactions and/or internal transformations to the previous ones: therefore, it could be considered as an "incremental" CA-model.

Subsequent releases of SCIDDICA were successfully applied to the $1984 \mathrm{Mt}$. Ontake, Japan, debris avalanche (Di Gregorio et al., 1999) and to the 1992 Tessina, Italy earth flow (Avolio et al., 2000). Recent applications concerned debris flows occurred in May 1998 at Pizzo d'Alvano, Italy (D'Ambrosio et al., 2002, 2003).

The Tessina earth flow was characterised by a rather slow velocity, up to few meters per day (Avolio et al., 2000): the resulting motion can be considered as purely gravitational, and modelled through the basic ("T") release of the model, 




Fig. 1. Portion of a 2-D-hexagonal cellular space. Integer coordinates $(x, y)$ individuate each cell of the cellular space. An example of neighbourhood - as utilised in SCIDDICA $\mathrm{S}_{3-\mathrm{hex}}$ - is also shown: the central cell $(0,0)$ and its six adjacent cells are marked in dark and light grey, respectively.

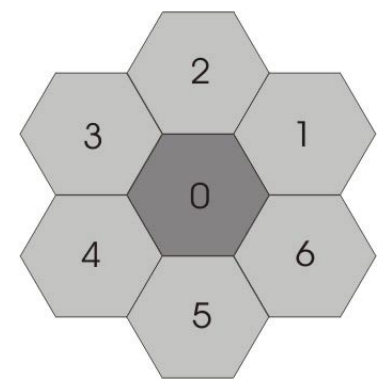

Fig. 2. The neighbourhood adopted in SCIDDICA $S_{3-h e x}$. Key: the central cell is individuated by the index " 0 "; indexes $1-6$ identify the cells of the neighbourhood.

in which the minimisation algorithm is implemented in its simplest form. Only two elementary processes constitute the transition function: $\langle a\rangle$ "debris outflows" (local interaction), and $\langle b\rangle$ "update of the landslide debris thickness" (internal transformation).

The release "O", applied to the Mt. Ontake landslide, is a crucial extension of the basic T-model (Di Gregorio et al., 1999): the considered case was, in fact, extremely rapid $(20-26 \mathrm{~m} / \mathrm{s})$ and thus characterised by relevant run-up effects (Sassa, 1988). As a consequence, the minimisation algorithm had to be modified, in order to account also for the ability of the flow of moving upslope and overriding topographic obstacles. Owing to the peculiar feature of the model, an empirical strategy was adopted: in the transition function, the process $\langle c\rangle$ "computation of the run-up" (local interaction) was considered (yet not satisfying the explicit treatment of inertial effects). At this purpose, it should be stressed that, in a context of data approximation (e.g. of the morphology), the treatment of vectorial proprieties can result very cumbersome, for the need of accounting also for frictional effects and related energy dissipation. Moreover, in such a context, modelling inertial effects should also account for changes of momentum induced either by obstacles or counterslope zones, which lead to modification of the flow direction mostly toward low ground areas. In particular, in case of very irregular morphology, obstacles produce high energy dissipation and turbulence, and flow direction statistically results downward. As a consequence, the adopted strategy of minimisation, opportunely enriched with the process $\langle c\rangle$, represent an adequate approximation even in case of very rapid flows, when the morphologic context is quite irregular and higher values of energy dissipation are hypothesised. On the other hand, in case of very regular morphology (e.g. flat areas or areas with uniform gentle slopes), energy dissipation is lower and momentum direction is less subject to abrupt changes: the proposed minimisation algorithm is expected to be less precise, mainly when handling cases of fast-moving flows.

The successive family " $\mathrm{S}_{x}$ " of SCIDDICA was developed for simulating the 1998 Sarno debris flows, which were characterised by strong soil erosion along the landslide path.

SCIDDICA $S_{1}$ (D'Ambrosio et al., 2003) introduced the elementary process of soil mobilisation, which was originally specified in two distinct phases: (1) direct activation of mobilisation, acted by the debris flow on the soil cover, and (2) propagation of the mobilisation to the neighbouring cells "by contact". The transition function is characterised by two more processes: $\langle d\rangle$ "mobilisation triggering and propagation" (local interaction, in two phases), and $\langle e\rangle$ "mobilisation effect" (internal transformation).

In SCIDDICA $S_{2}$ (D'Ambrosio et al., 2002) the computation of debris outflows $\langle a\rangle$ was improved, by introducing a more accurate calculation of the equilibrium conditions in the neighbourhood. As a consequence, the updated elementary process $\left\langle a^{\prime}\right\rangle$ "debris outflows" was derived.

Moreover, the elementary processes "update of the landslide debris thickness" $\langle b\rangle$ and "computation of the run-up" $\langle c\rangle$ were re-organised as follows: $\left\langle b^{\prime}\right\rangle$ "update of run-up and landslide debris thickness" (local interaction), and $\left\langle c^{\prime}\right\rangle$ "runup loss" (internal transformation).

SCIDDICA $S_{3}$, here described, has finally been derived by further on improving the process of soil mobilisation: a preliminary version, characterised by a square tessellation, has recently been presented by Iovine et al. (2002). In particular, the two phases which constituted the process "mobilisation triggering and propagation" $\langle d\rangle$ have been unified, and included into $\left\langle d^{\prime}\right\rangle$ "mobilisation triggering and effect" (internal transformation). Furthermore, the mechanism of "progressive soil erosion" has been introduced into the same process $\left\langle d^{\prime}\right\rangle$. For computational reasons, the elementary processes "update of run-up and landslide debris thickness" $\left\langle b^{\prime}\right\rangle$ and "run-up loss" $\left\langle c^{\prime}\right\rangle$ became: $\left\langle b^{\prime \prime}\right\rangle$ "update of landslide debris 
Table 1. List of the substates of SCIDDICA $\mathrm{S}_{3-\text { hex }}$

\begin{tabular}{cl}
\hline Substate & \multicolumn{1}{c}{ Meaning } \\
\hline$Q_{a}$ & Cell altitude (elevation of bedrock + depth of soil cover) \\
$Q_{t h}$ & Thickness of landslide debris \\
$Q_{e}$ & Energy of landslide debris \\
$Q_{d}$ & Depth of erodable soil cover \\
$Q_{o}$ & Debris outflow (from the central cell toward any cell of the neighbourhood) \\
\hline
\end{tabular}

thickness and energy" (local interaction), and $\left\langle c^{\prime \prime}\right\rangle$ "energy loss" (internal transformation).

In SCIDDICA $\mathrm{O}$ and $\mathrm{S}_{x}$ releases, two more internal transformations are included: $\langle f\rangle$ "water loss and related modification of landslide debris thickness", and $\langle g\rangle$ "altitude and landslide debris thickness modification by solidification". These have never been tested in the performed simulations of real cases, and have been eliminated, thanks to the particularly "wet" conditions which characterised the examined landslide activations.

The tessellation of the cellular space for SCIDDICA is square or hexagonal: commonly, the square tessellation allows for a quick test of the model, and is therefore utilised either in the preliminary phases of development of a release or for first calibration and analyses. The hexagonal tessellation is utilised in a successive phase, when a higher precision is needed. Note that the hexagonal tessellation permits a greater number of possible flow directions, and thus better approximations.

In literature, other examples of CA (or CA-like) models for flow-like landslides can be found. Among the most recent, cf. e.g. studies by Barca et al. (1986, 1987), Sassa (1988), Segre and Deangeli (1995), Malamud and Turcotte (1999, 2000), Clerici and Perego (2000), and Klenov (2000).

\section{SCIDDICA $S_{3-\text { hex }}$}

The release $\mathrm{S}_{3-\text { hex }}$ of SCIDDICA can be defined as follows:

SCIDDICAS $_{3-\text { hex }}=\langle R, X, Q, P, \sigma\rangle$

where

- $R=\left\{(x, y) \in \mathbb{Z}^{2} \mid-l_{x} \leq x \leq l_{x},-l_{y} \leq y \leq l_{y}\right\}$, identifies the hexagonal cellular space (Fig. 1); $\mathbb{Z}$ is the set of the integer numbers.

- $X=\langle(0,0),(1,0),(0,1),(0,-1),(-1,0),(-1,1)$, $(1,-1)\rangle$ is the geometrical pattern of the neighbourhood of the cell, given by the "central" cell and its six adjacent cells (cf. Fig. 1). Indexes are attributed to the neighbouring cells, in order to specify the rules of the transition function: " 0 " identifies the central cell, " $1-6$ " identify the adjacent cells (Fig. 2);

- $Q=Q_{a} \times Q_{t h} \times Q_{e} \times Q_{d} \times Q_{o}^{6}$ is the finite set of states of the $f a$, given by the Cartesian product of the sets of the considered substates. The value of the substate $x$ in the cell is expressed by $q_{x} \in Q_{x}$. In Table 1 , substates of $\mathrm{S}_{3-\text { hex }}$ are listed and defined.

- $P=\left\{p_{a}, p_{t}, p_{a d h}, p_{f}, p_{r}, p_{r l}, p_{m t}, p_{e r}\right\}$ is the set of the global (physical and empirical) parameters, whose meaning is specified in Table 2 .

- $\sigma: Q^{7} \rightarrow Q$ is the deterministic state transition function for the cells in $R$. It is constituted by the following elementary processes, listed in the order of application:

(1) mobilisation triggering and effect $\left\langle d^{\prime}\right\rangle$, internal transformation $T_{1}$

(2) debris outflows $\left\langle a^{\prime}\right\rangle$, local interaction $I_{1}$

(3) update of landslide debris thickness and energy $\left\langle b^{\prime \prime}\right\rangle$, local interaction $I_{2}$

(4) energy loss $\left\langle c^{\prime \prime}\right\rangle$, internal transformation $T_{2}$

At the beginning of each simulation ( $\operatorname{step} t=0$ ), the states of all the cells in $R$ must be specified, by defining the initial $\mathrm{CA}$ configuration. Initial values are given to the considered substates as follows:

- $q_{a}$ is set equal to the altitude (bedrock elevation plus depth of soil cover); in the landslide source, the thickness of the landslide debris is subtracted from the morphology;

- $q_{t h}$ is zero everywhere - except for the source area, where the landslide debris thickness is specified;

- $q_{e}$ is zero everywhere - except for the source area, where it is equal to the potential energy of the landslide (with reference to the cell altitude);

- $q_{d}$ is the depth of the soil cover, which can be eroded by the landslide along the path;

- $q_{o}$ are zero everywhere.

The transition function $(\sigma)$ is then applied, step by step, to all the cells in $R$, and the CA configuration changes: in this way, the evolution of the simulation is obtained.

The geometrical regularity of the cellular space allows for some computational simplification: e.g. the thickness can be employed to express the volume of landslide debris in a given cell. Accordingly, the elements of $Q_{a}$ are expressed as 
Table 2. List of the global parameters of SCIDDICA $S_{3-\text { hex }}$

\begin{tabular}{cl}
\hline Parameters & \\
\hline$p_{a}$ & Apothem of the cell \\
$p_{t}$ & Time correspondence of a CA step \\
$p_{a d h}$ & Adhesion (i.e. unmovable amount of landslide debris) \\
$p_{f}$ & Height threshold (related to friction angle) for debris outflows \\
$p_{r}$ & Relaxation rate for debris outflows \\
$p_{r l}$ & Run-up loss (at each step), due to frictional effects \\
$p_{m t}$ & Activation threshold for mobilisation of the soil cover \\
$p_{e r}$ & Parameter of progressive erosion of the soil cover \\
\hline
\end{tabular}

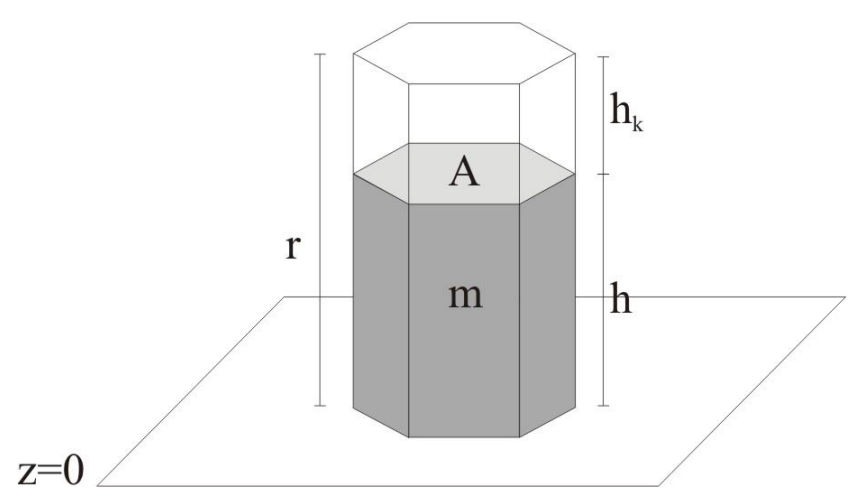

Fig. 3. Exemplification of "potential energy" in the CA context: a debris column (with base $=A$, height $=h$, kinetic head $=h_{k}$, run-up $=r$, and mass $=m$ ) is shown on the plane $z=0$.

length; the same is for the elements of $Q_{t h}$ and $Q_{d}$, which represent amount of material (thickness and depth); $Q_{o}$ is expressed in terms of length for reasons of computational homogeneity; the elements of $Q_{e}$ are finally expressed in the energy dimensions.

The following conventions are adopted in the following text: (1) indexes, specifying the cells of the neighbouring, are added between brackets to $q_{x} \in Q_{x}$, when the substates of all the neighbourhood are considered: e.g. the value of substate $x$ of the cell with index $a$ is given by $q_{x}(a)$; (2) the six values $q_{o}$ of the substates outflows need further specifications: $q_{o}(a, b)$ is the value of the outflow from the cell $a$ toward the cell $b$ of the neighbourhood (i.e. the value of the inflow into cell $b$ from the cell $a$ ).

\subsection{General considerations}

The peculiarity of the CA approach doesn't permit to make velocity explicit in the local context of the cell: an amount moves from the central cell to an adjacent cell in a CA step (which is a constant time), implying a constant "velocity". Nevertheless, velocities can be deduced by analysing the global behaviour of the system (Succi et al., 1988).

The following hydraulics considerations (Marchi and Rubatta, 1981) can help for deducing velocity and energy in a
CA context: the "kinetic head" is defined as $h_{k}=v^{2} / 2 g$, where $v$ is the speed of the flow and $g$ is the constant of gravity acceleration. Accordingly, the run-up $(r)$ can be defined as the height that be reached by the flow (cf. Fig. 3): $r=h+v^{2} / 2 g=h+h_{k}$, where $h$ is the thickness of the flow.

In the following description, energetic considerations are referred to potential energy and its variations, in the local context of the CA.

At this purpose, let's consider a column of base $A$, mass $m$ and height $h$ on the plane $z=0$ (Fig. 3). Its potential energy is given by:

$U=\rho g A \int_{0}^{h} z d z=\rho g A\left[\frac{z^{2}}{2}\right]_{0}^{h}=\frac{\rho g A}{2} h^{2}$

where $\rho$ is the density of the material that constitutes the column.

The kinetic-head effect can be inserted in Eq. (3), by "virtually" incrementing the height of the column from $h$ to $r$. As the mass must be conserved, a new density $\rho^{\prime}$ is derived:

$\rho^{\prime}=\frac{h}{r} \rho<\rho$

and the following "potential energy"-like formula expresses the energy increase:

$U^{\prime}=\frac{\rho^{\prime} g A}{2} r^{2}=\left(\frac{h}{r} \rho\right) \frac{g A}{2} r^{2}=\frac{\rho g A}{2} h r>U$

$U^{\prime}$ represents the energy $q_{e}$ (referred to the cell altitude), $h$ represents $q_{t h}$ in the frame of SCIDDICA $\mathrm{S}_{3-\mathrm{hex}}$, and $q_{e}$ is defined as:

$q_{e}=\frac{\rho g A}{2} q_{t h} \cdot r$

The product $\rho g A / 2$ can be considered as constant: in fact, $A$ is the cell area, and $\rho$ can be considered constant in the applications of the model. Therefore, $r$ is proportional to $q_{e} / q_{t h}$ by a constant $k=2 / \rho g A$ :

$r=\frac{2 q_{e}}{\rho g A q_{t h}}=\frac{k q_{e}}{q_{t h}}$ 

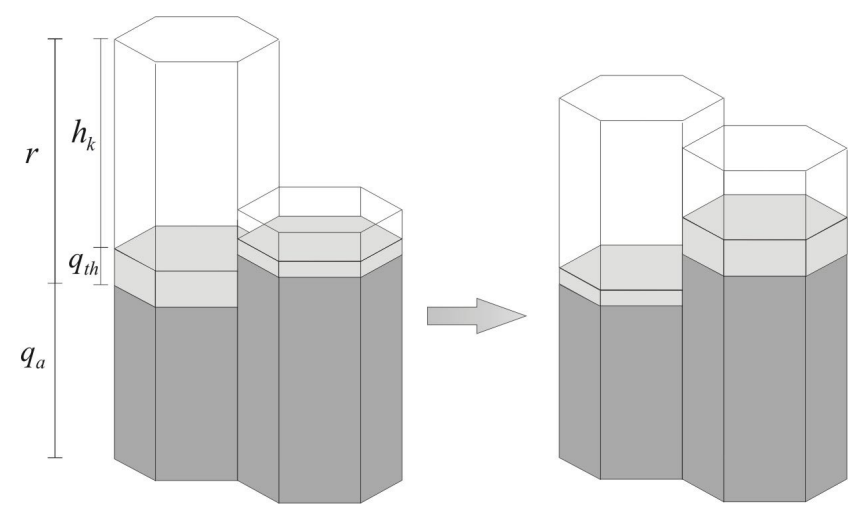

Fig. 4. Example of transition: on the left, the situation at step $t$; on the right, at step $t+1$. A case of debris outflow from a cell towards another one (this latter characterised by a higher height) is shown.

In Fig. 4, an example of outflow towards a cell characterised by higher height (given by altitude plus landslide debris thickness) is shown: the described distribution of landslide debris is permitted by the assumed energetic context (for a more detailed explanation of the distribution algorithm adopted in $\mathrm{S}_{3-\text { hex }}$, cf. the following section). In Fig. 5, the kinetic head $\left(h_{k}\right)$ and the run-up $(r)$, and the cell substates altitude $\left(Q_{a}\right)$, soil cover depth $\left(Q_{d}\right)$, and landslide debris thickness $\left(Q_{t h}\right)$ are shown; moreover, an ideal vertical section of a debris flow along a slope is also given.

\subsection{The transition function of SCIDDICA $\mathrm{S}_{3-\text { hex }}$}

In the following sections, a description of the four elementary processes which constitute the transition function of SCIDDICA $\mathrm{S}_{3-\text { hex }}$ is presented.

\subsection{1 $I_{1}$ : debris outflows}

The local interaction:

$I_{1}: Q_{a}^{7} \times Q_{t h}^{7} \times Q_{e} \times p_{a d h} \times p_{r} \times p_{f} \rightarrow Q_{o}^{6}$

determines the debris outflows from the central cell towards its adjacent cells.

It is based on an opportune minimisation algorithm, derived from the "minimization of the differences" proposed by Di Gregorio and Serra (1999). In order to account for the run-up effects, the height of the debris column in the central cell is "virtually" incremented from $h=q_{t h}(0)$ to $r=k q_{e}(0) / q_{t h}(0)$ (cf. previous section). Obtained outflows have to be normalised by a factor $v_{n f}=h / r=k q_{t h}^{2}(0) / q_{e}(0)$.

In the context of this minimisation algorithm (cf. §2.3),

$q(0)=q_{a}(0)+p_{a d h} ; \quad p=k q_{e}(0) / q_{t h}(0)-p_{a d h} ;$

$\left.q(i)=q_{a}(i)+q_{t h}(i), 1 \leq i \leq 6\right) ; \quad f(i), 0 \leq i \leq 6$,

are the not normalised outflows. The set $A$ comprises the cells that may receive flows; at the beginning of the algorithm, $A$ includes all the neighbouring cells.
The minimisation algorithm is composed of the following steps:

1. The angles $\beta_{i}$, specified by the differences in height between the central cell $\left(q(0)+p=q_{a}(0)+\right.$ $\left.k q_{e}(0) / q_{t h}(0)=q_{a}(0)+r\right)$ and the adjacent cell $i$ $\left(q(i)=q_{a}(i)+q_{t h}(i), 1 \leq i \leq 6\right)$ are computed (Fig. 6); the cell $i$ with $\beta_{i}<p_{f}$ is eliminated from $A$;

2. The following average is computed, considering the set $A$ of not-eliminated cells (where $\# A$ is the cardinality of the set $A$ ):

$$
\text { average }=\left(p+\sum_{i \in A} q(i)\right) / \# A
$$

3. The cell $i$ with $q(i) \geq$ average is eliminated from $A$; if any cell is eliminated, go back to step 2;

4. The flows $f(i)(0 \leq i \leq 6)$ towards the adjacent cells are computed as follows:

$$
\begin{aligned}
& f(i)=\text { average }-q(i) \quad(\text { if } i \in A) \\
& f(i)=0 \quad \text { (if } i \notin A) .
\end{aligned}
$$

The six values $q_{o}(0, i)(1 \leq i \leq 6)$ of the substates "outflows" from the central cell toward the adjacent cells are obtained, considering the normalisation factor $v_{n f}$ :

$q_{o}(0, i)=v_{n f} f(i) \quad(1 \leq i \leq 6)$

In Fig. 7, an example of the adopted minimization algorithm is shown.

\subsection{2 $I_{2}$ : update of landslide debris thickness and energy}

The local interaction:

$I_{2}:\left(Q_{t h} \times Q_{e} \times Q_{o}^{6}\right)^{7} \rightarrow Q_{t h} \times Q_{e}$

updates the values $q_{t h}$ and $q_{e}$ of the substates landslide debris thickness and energy.

The new value of landslide debris thickness $\left(\right.$ new $\left.q_{t h}\right)$ is obtained by considering debris thickness variations, due to outflows and inflows from/into the central cell:

new $q_{t h}=q_{t h}(0)+\sum_{i=1}^{6}\left(q_{o}(i, 0)-q_{o}(0, i)\right)$

The new value of the energy (new $q_{e}$ ) is obtained by considering energy variations, due to outflows and inflows from/into the central cell. Note that, in the computation, energy must be referred to the altitude of a same cell, i.e. the central cell:

$$
\begin{array}{r}
\text { new } q_{e}=\left(q_{\text {th }}(0)-\sum_{i=1}^{6} q_{o}(0, i)\right) \cdot\left(\frac{q_{e}(0)}{q_{t h}(0)}\right) \\
+\sum_{i=1}^{6}\left(q_{o}(i, 0) \cdot\left(\frac{q_{e}(i)}{q_{t h}(i)}\right)\right)
\end{array}
$$




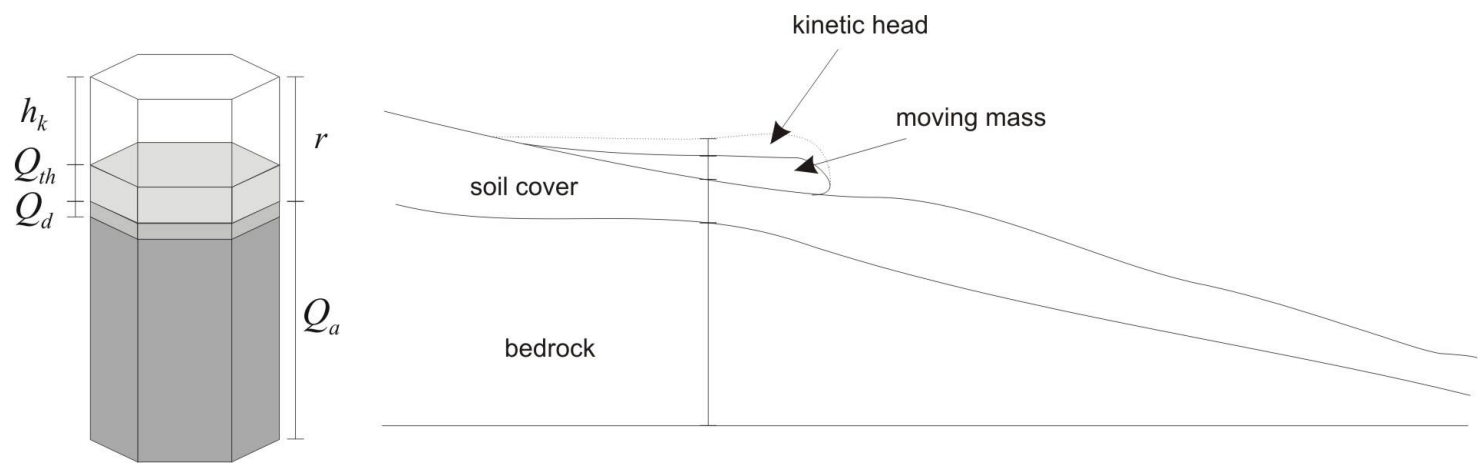

Fig. 5. Relationships among kinetic head $\left(h_{k}\right)$ and "run-up" $(r)$, and cell substates "altitude" $\left(Q_{a}\right)$, "soil cover depth" $\left(Q_{d}\right)$, and "landslide debris thickness" $\left(Q_{t h}\right)$, are shown. Moreover, an ideal vertical section of a debris flow along a slope is also given.

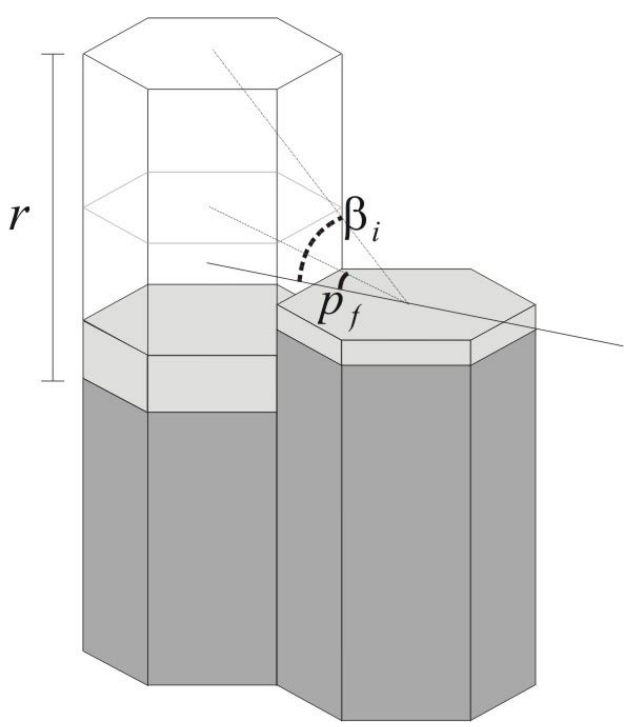

Fig. 6. Representation of the friction angle: $\beta_{i}$, representing the angle between the central cell (cell on the left) and its $i$-th neighbouring cell (cell on the right), is larger than the friction angle, $p_{f}$, then a flow can occur from the central cell.

\subsection{3 $T_{1}$ : mobilisation triggering and effect}

The internal transformation:

$$
\begin{aligned}
& T_{1}: Q_{a} \times Q_{e} \times Q_{t h} \times Q_{d} \times p_{e r} \times p_{m t} \\
& \rightarrow Q_{a} \times Q_{e} \times Q_{t h} \times Q_{d}
\end{aligned}
$$

determines the soil erosion and its effects.

The erosion condition is: $q_{e}(0)>p_{m t}$; the eroded quantity of the soil cover is $\Delta_{d}=\left(q_{e}(0)-p_{m t}\right) p_{e r}$ if $\Delta_{d}<q_{d}(0)$ else $\Delta_{d}=q_{d}(0)$.

The following new values update, respectively, the substates altitude, depth of soil cover, landslide debris thickness, and run-up:

new $q_{a}=q_{a}(0)-\Delta_{d}$

$$
\begin{aligned}
& \text { new } q_{d}=q_{d}(0)-\Delta_{d} \\
& \text { new } q_{t h}=q_{t h}(0)+\Delta_{d} \\
& \text { new } r=r+\Delta_{d}
\end{aligned}
$$

The energy is computed with reference to landslide debris thickness and run-up (both changed), and updated according to the following formula:

$$
\begin{aligned}
\text { new } & q_{e}=k\left(q_{t h}(0)+\Delta_{d}\right)\left(r+\Delta_{d}\right) \\
& =k q_{t h}(0) r+k r \Delta_{d}+k q_{t h}(0) \Delta_{d}+k \Delta_{d}^{2} \\
& =q_{e}(0)+q_{e}(0) \Delta_{d} / q_{t h}(0)+k\left(q_{t h}(0) \Delta_{d}+\Delta_{d}^{2}\right)
\end{aligned}
$$

\subsection{4 $T_{2}$ : energy loss}

The internal transformation:

$T_{2}: Q_{e} \times Q_{t h} \times p_{r l} \rightarrow Q_{e}$

determines the energy loss by friction. It is modelled, by reducing the run-up $r$ to a value - not lower than $q_{t h}(0)-$ by the parameter $p_{r l}$.

The loss of run-up is $\Delta_{r}=p_{r l}$ if $\left(k \cdot q_{e}(0) / q_{t h}(0)-p_{r l}\right)>$ $q_{t h}(0)$ else $\Delta_{r}=k \cdot q_{e}(0) / q_{t h}(0)-q_{t h}(0)$. It implies an energy updating:

new $q_{e}=q_{e}(0)-k \cdot \Delta_{r} \cdot q_{t h}(0)$

\section{Examples of application}

4.1 The May 1998 event in the Pizzo d'Alvano study area

On 5-6 May 1998, hundreds of soil slip-debris flows were triggered by heavy rains in Campania, mostly on the slopes of Pizzo d'Alvano massif (Del Prete et al., 1998). Debris slides originated in the soil mantle, and transformed into rapid/extremely rapid debris flows, deeply eroding the soil cover along their path. Landslides impacted on the urbanised areas at the base of the massif, causing serious damage and numerous victims.

Mesozoic carbonate rocks (Ippolito et al., 1975; Bonardi et al., 1988) mainly constitute the skeleton of the Campanian 


\begin{tabular}{|c|c|c|c|c|}
\hline $\begin{array}{l}\text { Configuration } \mathbf{t}=\mathbf{0} \\
q_{a}(0)=16, r=2, \\
q_{t h}(0)=1, p_{\text {adh }}=0 \\
p=2 ; q(0)=16 \\
q(1)=14 ; q(2)=20 ; \\
q(3)=20 ; q(4)=19 ; \\
q(5)=15 ; q(6)=14 \\
p_{f}=0^{\circ}\end{array}$ & $\begin{array}{l}\text { Step 1 } \\
\text { The cells } 2,3 \text { and } 4 \\
\text { are eliminated: } \\
\text { average }=15.25\end{array}$ & $\begin{array}{l}\text { Step } 3 \\
\text { The cell } 0 \text { is } \\
\text { eliminated: }\end{array}$ & $\begin{array}{l}\text { Step } 3 \\
\text { The cell } 5 \text { is } \\
\text { eliminated: }\end{array}$ & $\begin{array}{c}\text { No cell is eliminated } \\
\frac{\text { Step 4 }}{\left(p_{r}=0.6\right)} \\
f(1)=f(6)=0.5 ; \\
q_{o}(0,1)=q_{o}(0,6)= \\
=1 \cdot 0.5 \cdot 0.6=0.3 \\
20\end{array}$ \\
\hline
\end{tabular}

Fig. 7. Example of the minimisation algorithm adopted in SCIDDICA $S_{3-\text { hex }}$ for the determination of the outflows from the central cell towards its neighbouring cells.

Apennines (Southern Italy). Weathered and reworked pyroclastics of the Somma-Vesuvius volcanic complex (Arnò et al., 1987) mantle Pizzo d'Alvano massif: their thickness ranges from centimetres to meters, depending on slope, morphology and erosion processes. Soil characteristics are heterogeneous, varying with parent eruption and successive geomorphic history.

A detailed survey of the 1998 event was carried out, both in the field and through interpretation of air-photos, and a 1:5000 scale map of the disaster was realised (Iovine et al., unpublished). By this way, required information for calibration of SCIDDICA in the study area were collected.

Input matrices, employed to defining the initial values of the model substates for the entire cellular space, consist of: (1) elevation data, derived from 1:5000 scale topographic maps; (2) depth of erodable soil cover, as extrapolated after direct field surveying either along the path of the 1998 landslides or the main drainages; (3) location and extent of the landslide sources.

In Figs. 8a, 9a and 10a, three examples of the main landslides triggered on the southern slope of Pizzo d'Alvano in May 1998 are shown. The Chiappe di Sarno debris flow (Fig. 8a) is peculiar insofar as, after an initial track along a plane-convex segment of slope, the debris flow subdivided in two secondary flows, each captured by a distinct drainage; the same flows re-joined in the distal portion, at the base of the massif, causing serious damage to the urban setting in the Curti area. The Curti case of study (Fig. 9a) started, not far from the Chiappe di Sarno source, as a minor soil slip right above a sharp break in slope, related to a bedrock outcrop. The phenomenon rapidly propagated donwslope, entering the main channel and notably increasing its original volume by eroding the available regolith along the path; moreover, four secondary soil slips were triggered by the flowing mass on both flanks of the channel, in the middle portion of the path. At the base of the massif, the phenomenon subdivided into two distinct branches; these latter rejoined in proximity of the Curti area, impacting against the buildings and taking two lives. The Pestello Storto landslide (Fig. 10a) was also triggered on the southern slope of Pizzo d'Alvano, at the western border of the area affected by the event. The evolution of the uppermost segment of the Pestello Storto case is quite simple: as in the Curti case of study, it is an example of channelised flow, originated right above a natural break in slope; one secondary soil slip was also triggered by the main flow on the right flank of the channel, in the middle reach of the path. On the other hand, in the distal portion, the flow impacted against an artificial wall (located on the downslope side of a street), partly stopping in the area immediately below the wall, and partly propagating for about 350 meters along a minor channel. After crossing another street (and impacting against another small wall), the phenomenon came to rest within an archaeological site of Roman age, filling up the depressed area in the centre of a small amphitheatre.

The above cited cases of debris flows have been selected for a preliminary calibration of the model, as described in the next session.

\subsection{Model calibration}

Morphometric data of the sources of the considered landslides are listed in Table 3: it can be seen that, in the case of Pestello Storto, the extension (in terms of both area and volume) of the original soil slip is by far greater than the remaining two cases. On the other hand, the same landslide developed downslope by affecting a total area $(R)$, which is notably smaller than in the other mentioned cases (about 8 times smaller, if compared to the Curti case of study - cf. Table 4). This could be explained by considering the more confined nature of the Pestello Storto landslide, and also the 


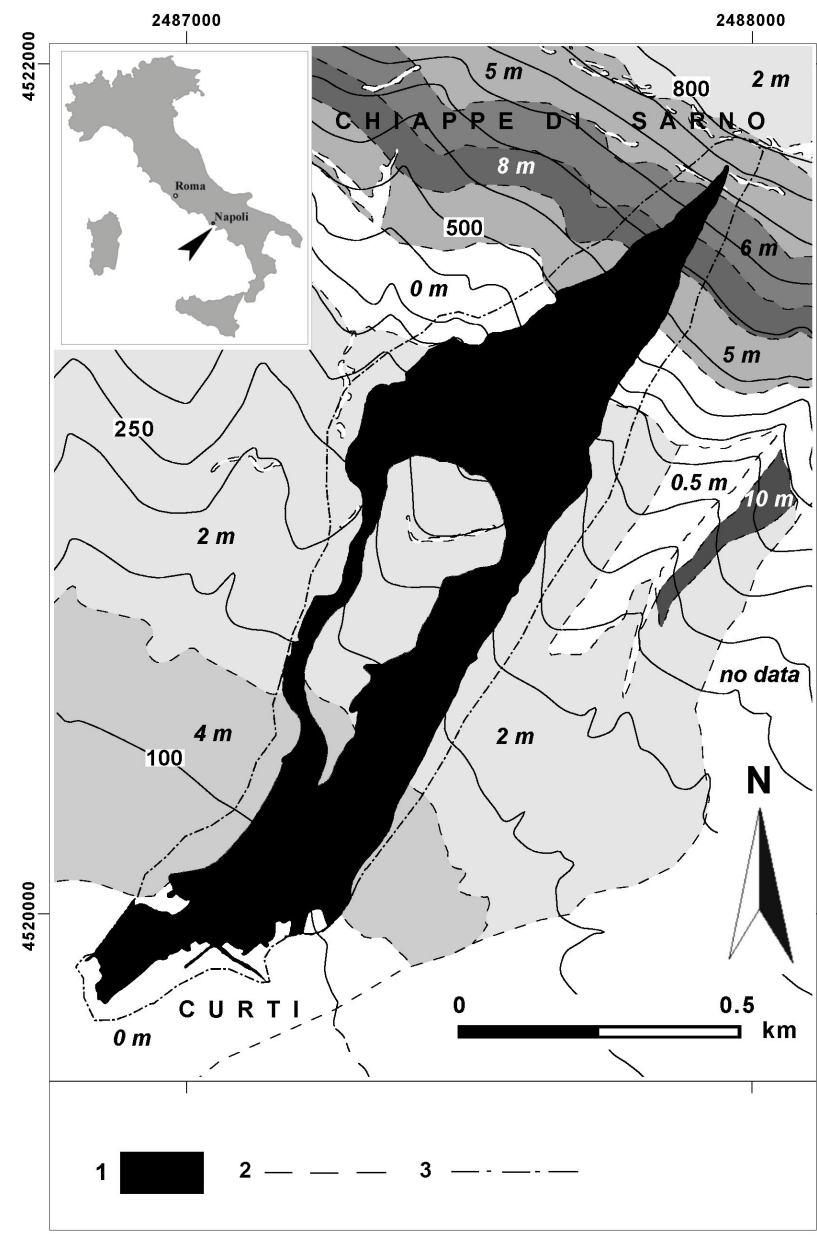

(a)

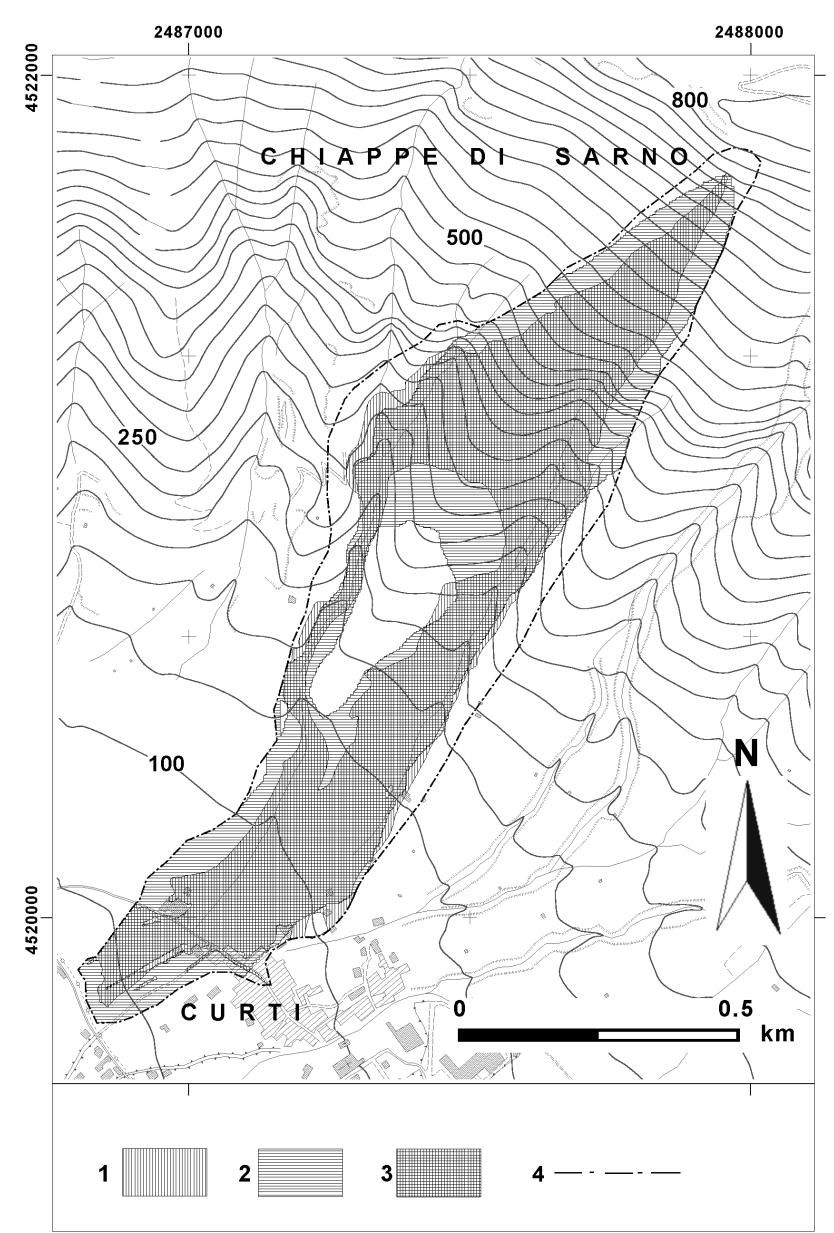

(b)

Fig. 8. (a) The Chiappe di Sarno landslide. Key: (1) area affected by the landslide; (2) limit of the zones with constant depth of soil cover (assumed values, in italics); (3) border of the area considered in the GIS analysis. (b) The Chiappe di Sarno landslide: quantitative comparison between real and simulated cases. Key: area affected by (1) real landslide, (2) simulated landslide, (3) both cases; (4) border of the area considered in the GIS analysis.

Table 3. Source morphometric characteristics of the considered landslides in the area of Pizzo d'Alvano massif

\begin{tabular}{lcccc}
\hline Case & $\begin{array}{c}\text { Length } \\
\mathrm{m}\end{array}$ & $\begin{array}{c}\text { Maximum width } \\
\mathrm{m}\end{array}$ & $\begin{array}{c}\text { Depth of soil cover } \\
\mathrm{m}\end{array}$ & $\begin{array}{c}\text { Area } \\
\mathrm{m}^{2}\end{array}$ \\
\hline Chiappe di Sarno & 4.7 & 8.7 & 5.0 & 29.8 \\
Curti & 5.9 & 11.6 & 2.0 & 68.3 \\
Pestello Storto & 10.1 & 14.3 & 6.0 & 102.6 \\
\hline
\end{tabular}

influence on the flow propagation of both the artificial wall and the amphitheatre, at the base of the massif.

For each case, by considering the best results of simulations (i.e. those characterised by minimum differences between simulated and real cases), optimal values were determined for the global parameters. A preliminary calibra- tion of the model was performed by first assigning values to the global parameters, both on the basis of their empiri$\mathrm{cal} /$ physical meaning and of previous simulations in similar areas of study (e.g. other case studies in the Pizzo d'Alvano area, and those in the San Martino Valle Caudina-Cervinara zone, Campania). Results were quantitatively analysed, in a 


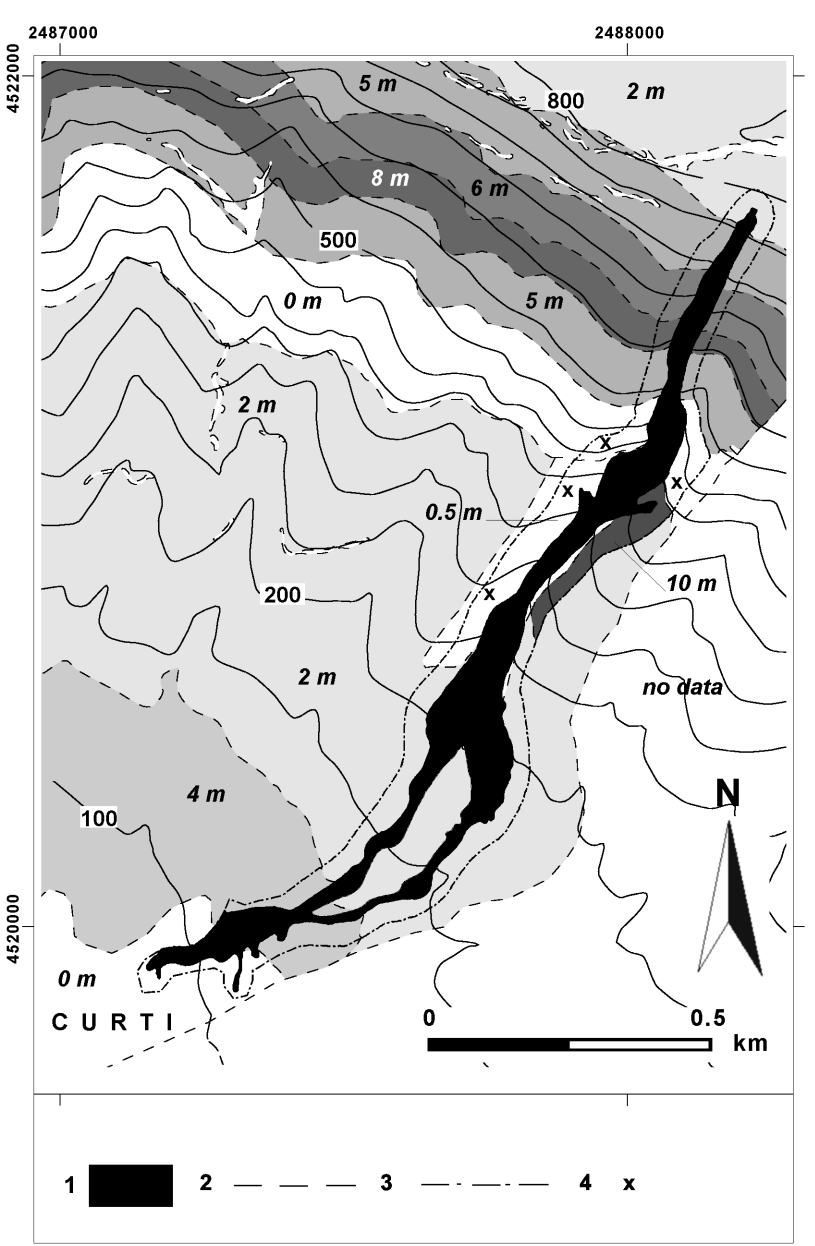

(a)

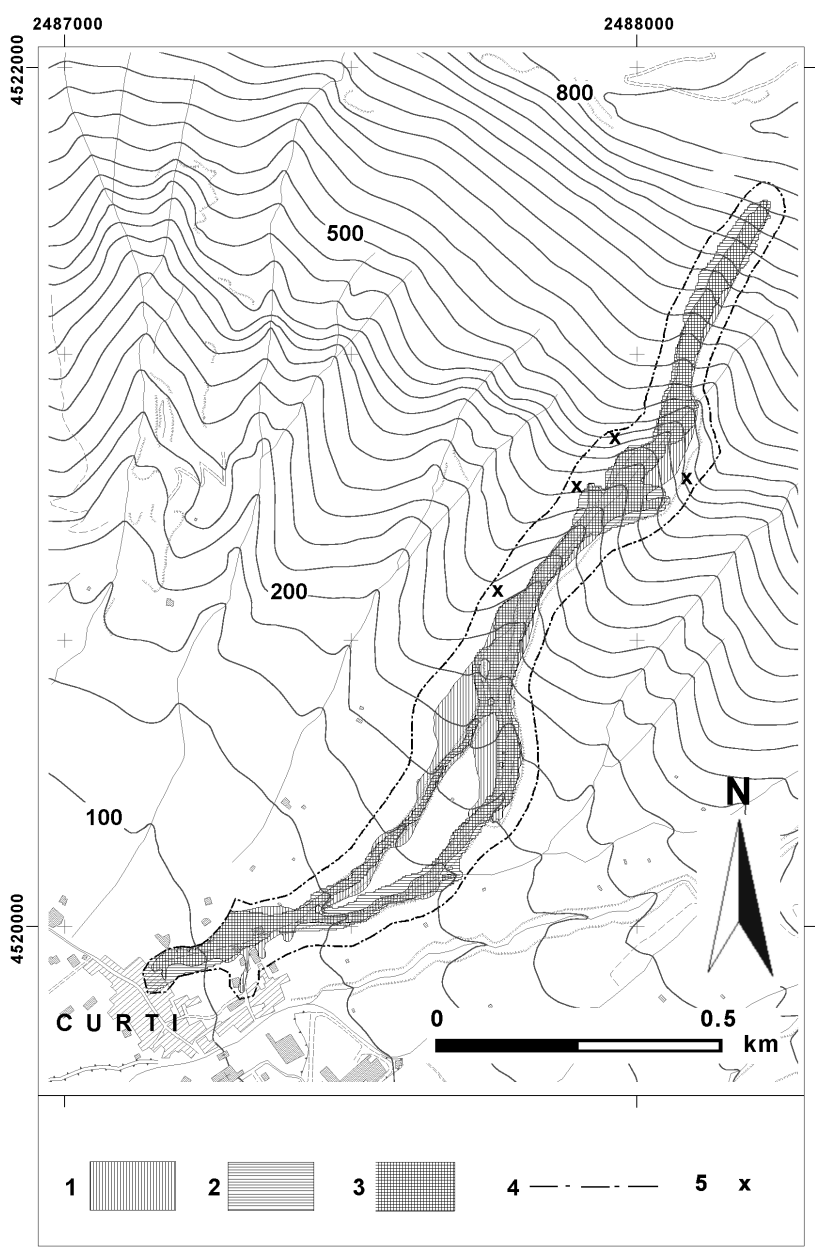

(b)

Fig. 9. (a) The Curti landslide. Key: (1-3) symbols as in Fig. 8a; (4) secondary source locations. (b) The Curti landslide: quantitative comparison between real and simulated cases. Key: (1-4) symbols as in Fig. 8b; (5) secondary source locations.

Table 4. Model calibration results for the considered landslides

\begin{tabular}{lcccccc}
\hline Case & $\begin{array}{c}R \\
\mathrm{~m}^{2}\end{array}$ & \multicolumn{1}{c}{$\begin{array}{c}S \\
\mathrm{~m}^{2}\end{array}$} & $\begin{array}{c}R \cap S \\
\mathrm{~m}^{2}\end{array}$ & $\begin{array}{c}R \cup S \\
\mathrm{~m}^{2}\end{array}$ & $e_{1}$ & $e_{2}$ \\
& \multicolumn{1}{c}{$\begin{array}{r}\text { Chiappe di Sarno } \\
319390\end{array}$} & 425660 & 300626 & 444423 & 0.82 & 0.97 \\
Curti & 104990 & 95334 & 75498 & 124826 & 0.78 & 0.85 \\
Pestello Storto & 40792 & 64116 & 30793 & 74114 & 0.64 & 0.87 \\
\hline
\end{tabular}

GIS (ARC/INFO) environment, through a back-analysis approach, by comparing the map of each real case with the simulated ones. Comparison was performed by verifying the areas affected by both (the real and the simulated) cases, and those affected by only one of them. The erosion/deposition character of the flows was also taken into account, in order to better evaluate the performed simulations. On the base of a trial-and-error method, values of parameters were succes- sively modified, aiming at obtaining better results.

Simulations were systematically compared to real cases, and errors quantitatively evaluated by considering the following indicators:

primary indicator $\left(e_{1}\right)=\sqrt{\frac{R \cap S}{R \cup S}}$ 


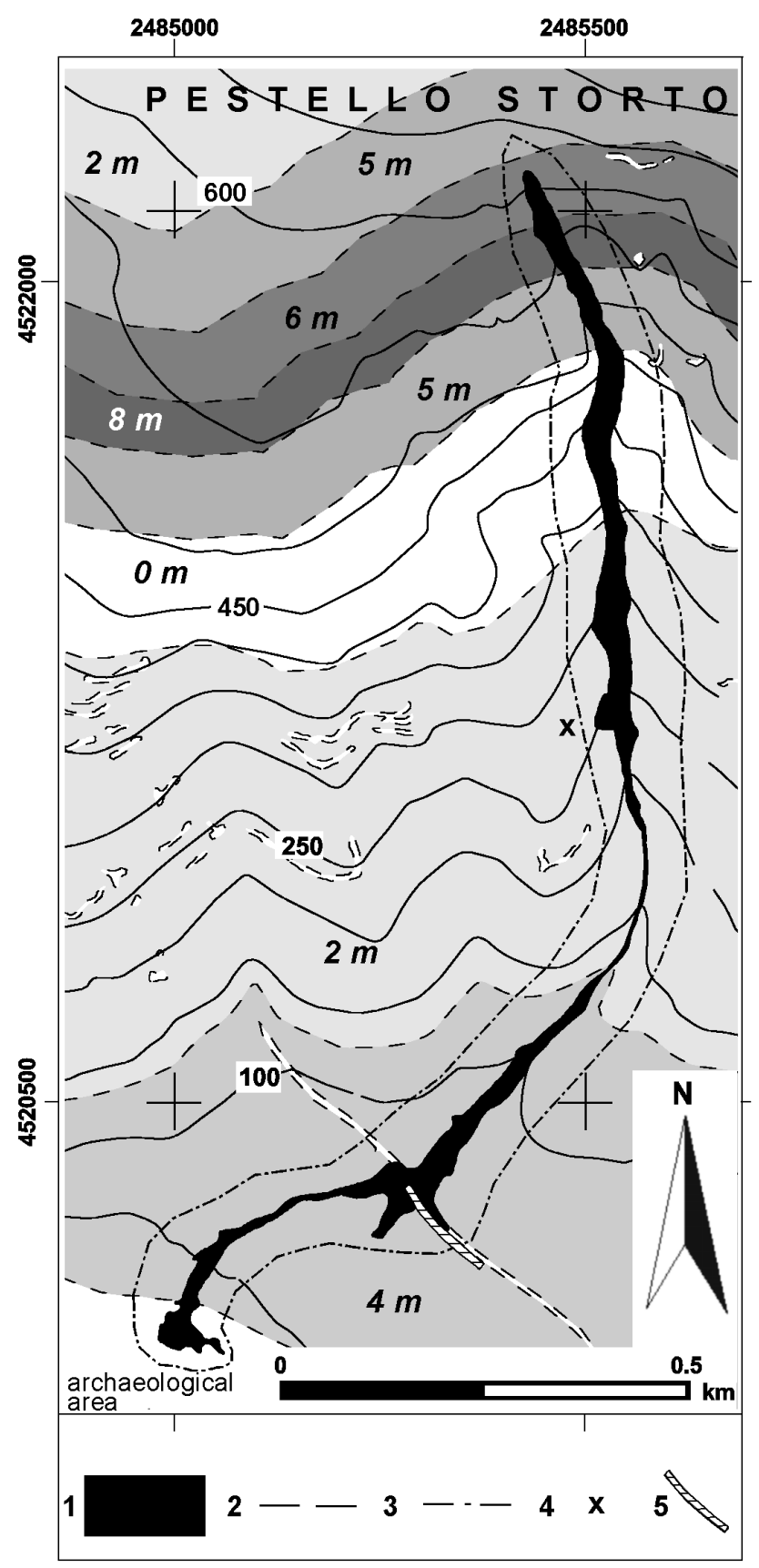

(a)

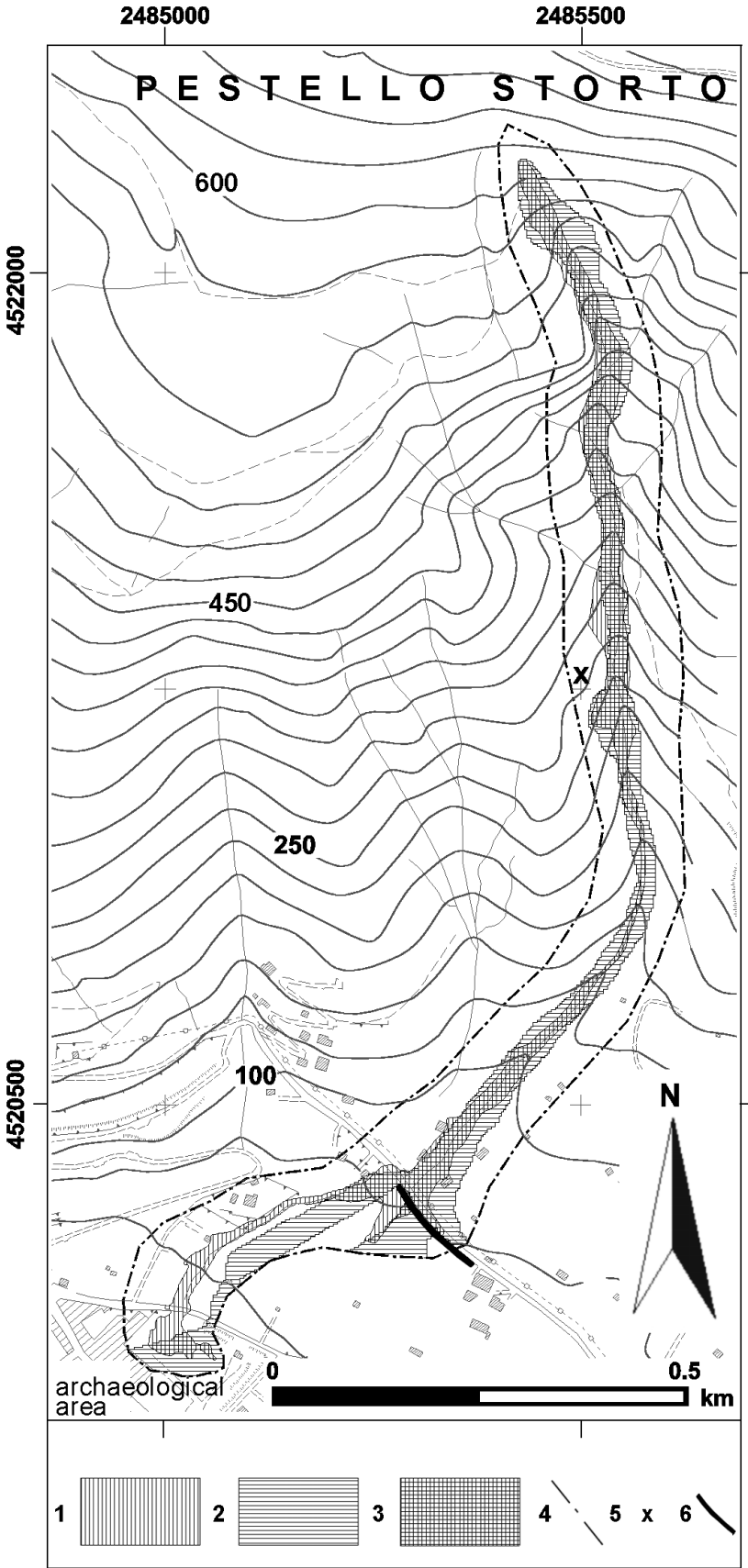

(b)

Fig. 10. (a) The Pestello Storto landslide. Key: (1-4) symbols as in Fig. 9a; (5) artificial wall along the border of the street. (b) The Pestello Storto landslide: quantitative comparison between real and simulated cases. Key: (1-5) symbols as in Fig. 9b; (6) artificial wall along the border of the street.

secondary indicator $\left(e_{2}\right)=\sqrt{\frac{R \cap S}{R}}$

where $R$ : the area affected by the real landslide; $S$ : the area involved by the simulation; $\cap$ : intersection; $\cup$ : union. Values of both indicators can range between 0 (i.e. complete unsuccess of simulation) and 1 (i.e. perfect simulation). Sim- ulations were judged "acceptable" only when the indicators showed values not exceeding pre-fixed thresholds of acceptability, fixed on the base of empirical considerations (as commonly done in statistical analysis). In the cases here considered, 0.7 and 0.85 could be selected as thresholds for $e_{1}$ and $e_{2}$, respectively - given the quality of the morphologic data 
available and the preliminary phase of analysis performed. Optimal values of global parameters were then iteratively determined, for the three considered cases of study, as follows: $p_{a}=1.25 \mathrm{~m} ; p_{a d h}=0.001 \mathrm{~m} ; p_{f}=0.1 \mathrm{~m} ; p_{r}=1$; $p_{r l}=0.6 \mathrm{~m} ; p_{m t}=3.5 \mathrm{~m}^{2} ; p_{e r}=0.015$.

Note that the model can be reliably applied only outside urbanised sectors, i.e. where soil erosion processes can properly be managed by the model; moreover, in such areas a greater morphological detail (compared to available topographic information) and engineering estimates on behaviour of human-made structures (in case of direct impact) would also be needed. As a consequence, $R$ and $S$ were computed outside the urbanised zone, within the areas delimited by dashed lines in Figs. 8, 9, and 10. Furthermore, the manmade wall, which greatly interfered with the evolution of the Pestello Storto landslide, had to be handled as an unerodable topographic alteration, by means of a specific additional input matrice.

Optimal parameters allow for the best results of simulation of the considered landslides. The performance of the model would certainly benefit from a systematic and automated calibration - e.g. in a parallel environment, by means of genetic algorithms (Di Gregorio et al., 1996): in this way, a proper definition of best values for global parameters could be attained, and the model could be confidently applied, either in the same study area or in an analogous geological context, for reliable predictive analyses. In this study, calibration has provisionally been performed on a standard PC platform, by manually assigning initial values to the parameters, and by modifying them on the basis of the analysis of the results. Therefore, a set of only "optimal" values (i.e. improvable) has been obtained for global parameters.

In Figs. 8b, 9b, and 10b, the comparisons among the real landslides and the best simulations are shown: from a qualitative point of view, the essential characters of the real cases are well captured. Furthermore, values of obtained indicators of error quite satisfy the prefixed thresholds for all the considered landslides (cf. Table 4). In particular: (a) the Chiappe di Sarno case of study shows the best results in terms of both primary and secondary indicators; (b) errors which characterise the Curti simulation are also acceptable, as previously assumed; (c) as regards the Pestello Storto landslide, its secondary indicator is pretty good, while the primary indicator barely satisfies prefixed quality requirements. This latter result could reasonably be ascribed to the poor quality of topographic data, especially in the flat area at the base of the massif (e.g. in such zone, the minor channel along which the distal portion of the phenomenon propagated can not be properly inferred by available topographic data).

\section{Conclusions}

The a-centric Weltanschauung (world-view) which characterises CA models involves a different viewpoint, with respect to partial differential equations, in treating complex macroscopic phenomena. Therefore, physics laws of conser- vation have to be rewritten (at a given approximation level) in a very different context of space-time discretisation. Values of model parameters cannot always be determined directly, e.g. by physical measures: they are commonly selected, in an iterative way, by comparing the results of simulations with the global behaviour of the real phenomenon. These values are then to be considered only as the "optimal combination" of such parameters, which allows the model to better simulate the considered phenomenon.

The range of applicability of the CA model strongly depends on its framework, in terms of elementary processes, substates and global parameters, which refer to the physical characteristics of the real phenomenon to be simulated. First, such a range can only be hypothesised, on the base of the characteristics of the local empirical laws considered in the transition function. The definitive judge on the validity of the model depends on the comparison between a large set of simulations (carried out by adopting several different sets of parameters' values) and the real phenomenon.

In its present release, the model is able to satisfactorily predict the evolution of flow-type slope movements, especially for cases not characterised by extremely rapid velocities. Among all the experiments carried out, the best applications regarded cases of slow-moving or moderately fast landslides; moreover, in case of high-speed phenomena, best results were obtained when developing on a rather rough morphology (Iovine et al., 2003b). In quantitative terms, the accuracy of the results can synthetically be expressed through indicators of error, which can be evaluated by comparing simulations with real cases, in a GIS environment.

By employing an incremental approach, an original simple model can gradually be enriched in order to simulate more complex phenomena. The evolution of SCIDDICA represents an example of such incremental approach, which permitted to progressively manage larger classes of flow-like landslides. Nevertheless, in the last release (here presented) some aspects still need to be treated. For example, (1) Water loss and debris solidification have not been implemented. Nevertheless, these processes could be important, especially in the final phase of a landslide. On the other hand, experimental data (frequently unavailable) can not be easily deducted from the global behaviour of the phenomenon. (2) Heavier inertial effects should be modelled, in order to better handling the influence of motion direction of the flowing mass. At this purpose, substates related to "momentum" components could be introduced in the model, aiming at considering the "privileged" direction of the flow. Such characteristic of the debris flow could be inferred, for instance, by considering both the kinetic head and the direction of the inflows into a given cell. A possible solution could involve two phases of computation for the debris distribution in the neighbourhood: in the former phase, the algorithm could determine the flows along the privileged direction (i.e. by assuming low energy dissipation conditions); in the latter, the present algorithm of minimisation could be applied (i.e. by considering high dissipation). Such a change in the model would represent an important improvement, espe- 
cially in cases of regular morphology and fast-moving flows. (3) Some of the global parameters could be transformed into substates - for instance, if a characteristic of the phenomenon (e.g. energy loss by friction) is not really "homogeneous" in the cellular space. (4) A further point which needs to be deeply investigated regards input data "reliability": results of simulations can, in fact, dramatically change, depending on data quality and precision. At present, efforts are mainly focused on the improvement of the management of inertial effects (the release $\mathrm{S}_{4}$ is undergoing preliminary testing).

Results obtained by applying SCIDDICA $\mathrm{S}_{3-\text { hex }}$ are significant: despite some minor diversity in the evolutionary style of the considered study cases, their development has satisfactorily been captured by the model. In fact, the areas affected by the debris flows and the thickness of the deposits have both been satisfactorily determined; indicators of error $\left(e_{1}\right.$ and $e_{2}$ ) show acceptable values - i.e. they do not appreciably exceed prefixed thresholds.

By means of a thorough phase of model calibration and validation, to be carried out in a systematic and automated way by considering a greater sample of real cases (of similar type within a homogeneous study area), the "best" set of global parameters could finally be obtained. Afterwards, by adopting such set, the model could be employed for true predictive purposes, in the same study area (or in a similar one), in order to estimating the evolution of new cases of landslide.

Applications of the model could therefore be useful in hazard mitigation: debris-flow susceptibility scenarios could be analysed as proposed by Iovine et al. b). Moreover, the effects of planned mitigation actions on flow evolution could be preliminary evaluated: in fact, in case of engineering works easily translatable into CA terms (such as stream deviations, channelling, embankments, which can be seen as topographic alterations), these could be handled as a specific substate and given as additional input matrice to the model. In the present study, the artificial wall which partly hampered the Pestello Storto debris flow at the base of the Pizzo d'Alvano massif has been treated just in accordance with such a modelling approach. By analysing the results of simulation, with and without engineering works, a betterfounded selection of the most suitable mitigation actions to be realised could finally be carried out.

\section{References}

Aleotti, P. and Chowdury, R.: Landslide hazard assessment: a summary review and new perspectives, Bull. Eng. Geol. Env., 58, 21-44, 1999.

Arnò, V., Principe, C., Rosi, M., Santacroce, R., Sbrana, A., and Sheridan, M. F.: Eruptive history, in: Somma-Vesuvius, edited by Santacroce, R., CNR-Quaderni della Ricerca Scientifica, CNR, Roma, Progetto Finalizzato "Geodinamica", 8, 53103, 1987.

Avolio, M. V., Di Gregorio, S., Mantovani, F., Pasuto, A., Rongo, R., Silvano, S., and Spataro, W.: Simulation of the 1992 Tessina landslide by a cellular automata model and future hazard scenarios, JAG, 2, 41-50, 2000.
Barca, D., Di Gregorio, S., Nicoletta, F. P., and Sorriso-Valvo, M.: A Cellular Space Model for Flow type Landslides, in: Proc. IASTED Int. Symp. "Computer and their application for Development", edited by G. Messina, G. and Hamzda, M. H., Taormina, Italy, September 1986, 30-32, 1986.

Barca, D., Di Gregorio, S., Nicoletta, F. P., and Sorriso-Valvo, M.: Flow-type landslide modelling by cellular automata, in: Proc. A.M.S. Int. Congress on Modelling and Simulation, Cairo, Egypt, March, 1987: 3-7, 1987.

Barca, D., Crisci, G. M., Di Gregorio, S., and Nicoletta, F.: Cellular Automata for simulating lava flows: a method and examples of the Etnean eruptions, Transport Theory and Statistical Physics, 23, 195-232, 1994.

Bonardi, G., D’Argenio, B., and Perrone, V.: Geologic map of Southern Apennines in scale 1:250 000, Mem. Soc. Geol. It., in Italian, 41, 1341, 1988.

Bromhead, E.: Pore-water pressure manipulation in computerised slope stability analysis, in: Computer Applications in Geotechnical Engineering, Midland Geotechnical Society, Birmingham, 175-184, 1986.

Burks, A. W.: Essays on cellular automata, University of Illinois Press, Urbana, 1970.

Carrara, A., Cardinali, M., Guzzetti, F., and Reichenbach, P.: GIS technology in mapping landslide hazard, in: Geographical Information Systems in Assessing Natural Hazards, edited by Carrara, A. and Guzzetti, F., 135-176, 1995.

Clerici, A. and Perego, S.: Simulation of the Parma River blockage by the Corniglio landslide (Northern Italy), Geomorphology, 33, 1-23, 2000.

D'Ambrosio, D., Di Gregorio, S., Gabriele, S., and Gaudio, R.: A Cellular Automata Model for Soil Erosion by Water, Physics and Chemistry of the Earth, B, 26, 33-40, 2001.

D’Ambrosio, D., Di Gregorio, S., Iovine, G., Lupiano, V., Rongo, R., and Spataro, W.: First simulations of the Sarno debris flows through cellular automata modelling, Geomorphology, 54, 91117, 2003.

D’Ambrosio, D., Di Gregorio, S., Iovine, G., Lupiano, V., Merenda, L., Rongo, R., and Spataro, W.: Simulating the Curti-Sarno Debris Flow through Cellular Automata: the model SCIDDICA (release S2), Physics and Chemistry of the Earth, 27, 1577-1585, 2002.

Del Prete, M., Guadagno, F. M., and Hawkins, A. B.: Preliminary report on the landslides of 5 May 1998, Campania, Southern Italy, Bull. Eng. Geol. Env, 57, 113-129, 1998.

Di Gregorio, S. and Serra, R.: An empirical method for modelling and simulating some complex macroscopic phenomena by cellular automata, Future Generation Computer Systems, 16, 259271, 1999.

Di Gregorio, S., Serra, R., and Villani, M.: Combining cellular automata and genetic search in complex environmental modelling, in: Proc. 3rd Systems Science European Congr., edited by Pessa, E., Penna, M. P., and Montesano, A., Roma (Italia), October 1-4, 1996, Ed. Kappa, Roma, 1127-1131, 1996.

Di Gregorio, S., Rongo, R., Siciliano, C., Sorriso-Valvo, M., and Spataro, W.: Mount Ontake landslide simulation by the cellular automata model SCIDDICA-3, Physics and Chemistry of the Earth, 24, 97-100, 1999.

Frisch, U., Hasslacher, B., and Pomeau, Y.: Lattice gas automata for the navier-Stokes equation, Phys. Rev. Lett., 56, 1505-1508, 1986.

Guzzetti, F., Carrara, A., Cardinali, M., and Reichenbach, P.: Landslide hazard evaluation: a review of current techniques and their 
application in a multi-scale study, Geomorphology, 31, 181-216, 1999.

Hardy, J., de Pazzis, O., and Pomeau, Y.: Molecular dynamics of a classical lattice gas: transport properties and time correlations functions, Phys. Rev., A, 13, 1949-1961, 1976.

Holland, J. H.: Adaptation in natural and artificial systems, University of Michigan Press, Ann Arbor, 1975.

Iovine, G., Di Gregorio, S., D'Ambrosio, D., and Lupiano, V.: Debris Flows and Cellular Automata: an example of simulation from the 1998 disaster of Sarno (Italy), in: Proc. Symp. "Geomorphology: from expert opinion to modelling", Strasbourg, France, April 26-27, 2002: SODIMPAL Imprimeur, Rouen, 5564, 2002.

Iovine, G., Di Gregorio, S., and Lupiano, V.: Debris-flow susceptibility assessment through cellular automata modeling: an example from 15-16 December 1999 disaster at Cervinara and San Martino Valle Caudina (Campania, southern Italy), Natural Hazards and Earth System Sciences, 3, 1-12, 2003a.

Iovine, G., Di Gregorio, S., and Lupiano, V.: Assessing debrisflow susceptibility through cellular automata modelling: an example from the May 1998 disaster at Pizzo d'Alvano (Campania, Southern Italy), in: Debris-Flow Hazards Mitigration: Mechanics, Prediction and Assessment; Proceedings of the Third International DFHM Conference, Davos, Switzerland, September 10 12, 2003, edited by Rickenmann, D. and Cheng, C. L., Millpress Sciences Publishers, Rotterdam, 623-634, 2003 b.

Iovine, G., Merenda, L., and Lupiano, V.: Surveying and digital cartography of the May 1998 disaster at Pizzo d'Alvano (Campania, Southern Italy), CNR-IRPI Rep. 98, unpublished.

Ippolito, F., D'Argenio, B., Pescatore, T. S., and Scandone, P.: Tectonic framework of the Southern Apennines and related structural-stratigraphic units, in: The guidebook to Italy, Petroleum Exploration Society of Lybia, Squyres, 317-328, 1973.

Johnson, A. M. and Rodine, J. R.: Debris flow, in: Slope Instability, edited by Brunsden, D. and Prior, D. B., John Wiley, New York, 257-361, 1984

Klenov, V. I.: 2-D debris-flow simulation, in: Debris-Flow Hazards Mitigation: Mechanics, Prediction, and Assessment, edited by Wieczorek, G. F. and Naeser, N. D., Proc. 2nd Int. Conf. on Debris-Flow Hazards Mitigation, Tapei (Taiwan), August 16-18, 2000, 547-550, 2000.

Kohonen T.: Self-organization and associative memory, Springer Verlag, Heidelberg, 1984
Little, A. L. and Price, V. E.: The use of an electronic computer for slope stability computation, Géotechnique, 8, 113-120, 1958.

Malamud, B. D. and Turcotte, D. L.: Self-organised criticality applied to natural hazards, Natural Hazards, 20, 93-116, 1999.

Malamud, B. D. and Turcotte, D. L.: Cellular Automata models applied to natural hazards, IEEE Computing in Science and Engineering, 2, 42-51, 2000.

Marchi, E. and Rubatta, A.: Meccanica dei fluidi. Principi e applicazioni, UTET, Torino, 1981.

McNamara, G. R. and Zanetti, G.: Use of the Boltzmann equation to simulate lattice-gas automata, Phys. Rev. Lett., 61, 2332-2335, 1988.

Morgenstern, N. R. and Price, V. E.: A numerical method for solving the equations of stability of general slip surfaces, Computer Journal, 9, 388-393, 1967.

Rothman, D. H. and Zaleski, S.: LatticeGas Cellular Automata: Simple Models of Complex Hydrodynamics, Cambridge Univ. Press, Cambridge, UK, 1997.

Sassa, K.: Motion of Landslides and Debris Flows, Report for Grant-in-Aid for Scientific Research, (Project No.61480062), Japanese Ministry on Education, Science and Culture, Tokyo, 1988.

Segre, E. and Deangeli, C.: Cellular Automaton for Realistic Modelling of Landslides, Nonlinear Processes in Geophysics, 2, 115,1995

Succi, S., Santangelo, P., and Benzi, R.: High-Resolution LatticeGas Simulation of Two-Dimensional Turbulence, Phys. Rev. Lett., 60, 2738-2743, 1988.

Succi, S., Benzi, R., and Higuera, F.: The lattice Boltzmann equation: a new tool for computational fluid dynamics, Physica, 47, 219-230, 1991.

Van Westen, C. J.: GIS in landslide hazard zonation: a review with examples from ndes, Colombia. in: Mountain Environment and GIS, edited by Price, M. F. and Heywood, D. I., London, Taylor and Francis, 135-165, 1994.

von Neumann, J.: Theory of self reproducing automata, University of Illinois Press, Urbana, 1966.

Withman, R. V. and Bailey, W. A.: Use of computers for slope stability analysis, J. Soil Mechanics Div., 93, 475-498, 1967.

Wolfram, S.: Theory and application of cellular automata, World Scientific, Singapore, 1986.

Wolfram, S.: A new kind of Science, Wolfram Media Inc., Champaign, 2002. 